NASA Technical Memorandum 104521

AIAA-91-2252

\title{
Analytical Combustion/Emissions Research Related to the NASA High- Speed Research Program
}

H. Lee Nguyen

Lewis Research Center

Cleveland, Ohio

Prepared for the

27th Joint Propulsion Conference

cosponsored by the AIAA, SAE, ASME, and ASEE

Sacramento, California, June 24-27, 1991

\section{N/SN}




\title{
ANALYTICAL COMBUSTION/EMISSIONS RESEARCH RELATED TO THE
}

\section{NASA HIGH-SPEED RESEARCH PROGRAM}

\author{
H. Lee Nguyen \\ National Aeronautics and Space Administration \\ Lewis Research Center \\ Cleveland, Ohio 44135
}

\begin{abstract}
Increasing the pressure and temperature of the engines of new generation of supersonic airliners increases the emissions of nitrogen oxides $\left(\mathrm{NO}_{\mathrm{x}}\right)$ to a level that would have an adverse impact on the Earth's protective ozone layer. In the process of evolving the implementing low emissions combustor technologies, NASA Lewis Research Center has pursued a combustion analysis program to guide combustor design processes, to identify potential concepts of greatest promise, and to optimize them at low cost, with short turnaround time. The approach is to upgrade and apply advanced computer programs for gas turbine applications. Efforts have been made in further improving the code capabilities of modeling the physics and the numerical method of solution. Then test cases and measurements from experiments are used for code validation.
\end{abstract}

To provide insight into the combustion process and combustor design, twodimensional and three-dimensional codes such as KIVA-II and LeRC3D have been used. These codes are operational and calculations have been performed to guide low emissions combustion experiments.

\section{$\underline{\text { Introduction }}$}

No ${ }_{x}$ emissions from current technology combustors are produced in the near stoichiometric primary zone at a rate that increases with flame temperature and residence time. As new engine cycles increase combustor inlet pressure and temperature, the $\mathrm{NO}_{\mathrm{x}}$ emissions increase correspondingly. Most low $\mathrm{NO}_{\mathrm{x}}$ combustor design concepts reduce $\mathrm{NOx}$ emissions by reducing flame temperature and oxygen availability for NOx formation. This can be accomplished by burning either fuel lean or fuel rich in the primary zone, thus avoiding high NOx formation at near stoichiometric conditions.

In the process of evolving and implementing low emission combustor technologies, NASA Lewis has pursued a combustion analysis code program to guide combustor design processes, to identify potential concepts of greatest promise, and to optimize them at low cost, with short turn-around time. The computational analyses are evaluated at actual engine operating conditions. The approach is to upgrade and apply advanced computer programs for gas turbine applications. Efforts have been made in further improving the code capabilities for modeling in the physics and the numerical method of solution. The test cases and measurements from experiments are used for code validation.

Due to schedule constraints, the High Speed Research (HSR) analytical research program is being conducted over a period of a little over 5 years as shown in Fig. 1 and involves the major milestones. The first milestone was accomplished with the development and use of two-dimensional and threedimensional codes, KIVA-II and LeRC3D, to guide low emissions combustion experiments. These codes will be updated based on results obtained from combustion concept experiments by the end of fiscal year 1995 .

The overall combustion analytical codes evolution plan involves in-house research and contracts and grants; and it provides strong collaborative relationships and technology transfer between industry, universities, and government agencies. Figure 2 lists the 
activities and the key participants for the HSR Combustion Analytical Research Program.

The remainder of the report describes in greater detail a description of computer codes used and representative results on low emission combustor calculations.

\section{Description of Computer Codes}

To provide insight into the combustion process and combustor design, KIVA-II and LeRC3D have been used. These codes are operational and calculations have been performed to guide low emissions combustion experiments.

\section{Description of Computer Code KIVA-II}

KIVA-II (Ref. 1) developed by Los Alamos National Laboratory, is one of the most developed and validated codes of the available for multi-dimensional prediction of the in-cylinder combustion dynamics in internal combustion engines. There are features of KIVA-II that make it well suited for other applications, so KIVA-II has been adapted for gas turbine combustor applications.

In terms of modeling the physics, the major features of KIVA-II are as follows (see Fig. 3):

- KIVA-II is two- and three-dimensional turbulent compressible flow solver of reacting multi-component gas mixture with liquid spray using an Eulerian-Lagrangian approach. model.

- Turbulence is modeled using the $\mathrm{k}-\varepsilon$

- Combustion is modeled by a chemicalkinetics-controlled model using global or detailed chemical reactions (Ref. 2) or by a mixing-controlled model (Ref. 3). The user can conveniently provide a chemical kinetics mechanism by making appropriate modification to the input data file (Ref. 2).
- The extended Zeldovich $\mathrm{NO}_{\mathrm{x}}$ mechanism is included.

- Stochastic particle spray model includes vaporization, coalescence, and breakup.

- A soot formation/oxidation and a radiative heat transfer model are also included:

In terms of numerics, KIVA-II is based on the following (see Fig. 3):

- Time-dependent finite-difference code with arbitrary mesh capability, using an implicit continuous Eulerian technique with conjugate residual iteration for the flow solver.

\section{Description of Computer Code LeRC3D}

LeRC3D is highly advanced code for gas turbine combustor applications. LeRC3D was developed by Carnegie Mellon University with the collaboration/sponsorship of Lewis. In terms of modelling the physics, the major capabilities of LeRC3D (Ref. 4) are as follows (see Fig. 4):

- LeRC3D is two- and threedimensional code that solves the N-S equations for turbulent compressible flow of reacting multi-component gas mixture with liquid spray using an Eulerian-Lagrangian approach.

- The turbulence is modeled by using a $\mathrm{k}-\varepsilon$ turbulence model with wall functions, or by using low Reynolds number k- $\varepsilon$ model of Chen and Patel, or by using a RNG-based $\mathrm{k}-\varepsilon$ model.

- Modeling of combustion is done by two different models: the chemical-kineticscontrolled model governed by global or detailed chemical kinetics mechanisms of hydrocarbon combustion, and the mixingcontrolled model of Magnussen and Hjertager. The user can conveniently provide a chemical kinetics mechanism by making appropriate modification to the input data file. 
- The chemical kinetics model used to study $\mathrm{NO}_{\mathrm{x}}$ is the Zeldovich mechanism.

- The spray model includes the fuel vaporization model of Raju and Sirinano.

In terms of the numerical method of solution, LeRC3D is based on the following (see Fig. 4):

- The flow algorithm is a finite-volume LU algorithm utilizing van Leer flux-vector splitting with the HOPE algorithm of Liou and Steffan. Source terms are treated implicitly using Shih and Chyu method, diffusion terms are treated implicitly using the procedure of Shih and Steinthorsson.

- A grid system is generated by using an algebraic grid generation method based on transfinite interpolation.

\section{$\underline{\text { Results and Discussion }}$}

Fuel Injection and Mixing

Figure 5 shows the prediction of a swirling fuel spray in a nonreacting airstream using the KIVA-II code and a comparison with the experimental results (Ref. 5). The model airassist atomizer embodies a nonswirl inner airstream and a swirling outer airstream which help to atomize and distribute fuel injected from a core tube. Predicted and measured air azimuthal velocity profiles are in good agreement. Fuel injection and mixing become increasingly important as more air is used for the combustion process. Detailed models of the interaction of the swirling air and the fuel spray can provide valuable insight into the effect of different variables that presently can only be evaluated experimentally on a global scale at laboratory test conditions.

As an integral part of the fuel nozzle calculations, two-dimensional and threedimensional analysis (Refs. 6 and 7 ) were done to provide the swirling air profiles through the swirlers of the airblast fuel nozzle. The swirl vane cascade analysis provides inlet air profiles to the combustor analyses. A systematic design procedure of advanced airblast fuel nozzle swirl vane assemblies resulted in low-loss, high-turning swirl vane designs were done. Figure 6(a) shows the velocity profile just downstream of the nozzle inlet. Note the velocity is high with a large swirling component. This is required for good fuel atomization. Figure 6(b) shows the velocity field further downstream in the combustor. The recirculation zone is evident by the negative axial velocity component.

$\underline{\text { Low } \mathrm{NO}_{\mathrm{x}} \text { Combustion Analyses }}$

Figure 7 summarizes the comparison of experimental $\mathrm{NOx}$ and $\mathrm{CO}$ emission index of a lean premixed prevaporized (LPP) burner (Ref. 9) with KIVA-II code predictions. The simplified kinetics mechanism (Ref. 2) was used. The predictions agree very well with the test data over the range of equivalence ratio and residence time reported. Calculations using KIVA-II have been performed to guide current low NOx combustion experiments.

KIVA-II was used to perform twodimensional analysis of the Rich Burn/Quick Quench/Lean Burn (RQL) combustor to provide detailed information on the combustor internal flow fields, fuel-air mixing, combustor emissions, gas temperature distribution, and pattern factor. A two-dimensional axisymmetric model was used with propane and primary air injected at the inlet of the rich burn section and quick quench air supplied to the two-dimensional slot in the quick quench section. The upper half above the combustor centerline showing the gas temperature profile is shown in Fig. 8. The rich zone and lean zone equivalence ratios were set at 1.4 and 0.65 , respectively. The gas temperature contours show core hot gas regions that occur in the rich zone and lean flame fronts. This figure also indicates that the penetration of the two-dimensional jet reaches near the combustor centerline and that thermal quenching occurs in the quick quench section. 
Three-dimensional analyses of the RQL combustor were performed using KIVA-II and the LeRC3D. Figure 9 shows velocity vectors typical of the quick quench-tenure section examined at an axial plane at a downstream location of half a slot length from the slot centerline (Ref. 10). There are twelve $45^{\circ}$ slanted slots located symmetrically around the perimeters of the quick quench section. The slots were rectangular in shape with a radius at both ends and with an aspect ratio of four and the momentum flux ration considered for this case is 60 . The quick quench section was sandwiched between the converging section of the rich burner exit and the diverging section of the lean burner inlet. One of the most striking physical features of quick quench jet injected normally into the mainstream from $45^{\circ}$ slanted slots in the appearance of the swirling flow field shown in Fig. 9. This swirling flow field is responsible for the quick mixing required for low $\mathrm{NO}_{\mathrm{x}}$ formation in the quick quench section of the RQL combustor calculated using KIVA-II. Figure 10 shows the velocity vectors and a strong central recirculation zone downstream of the airblast fuel nozzle. Calculations using LeRC3D have been performed to guide low $\mathrm{NO}_{\mathrm{x}}$ combustion experiments.

\section{Concluding Remarks}

As physical submodels and numerics accuracy improve, analytical models play a vital role in the design and development process of low emissions combustors. In spite of deficiencies such as accurate chemical kinetics modeling of hydrocarbon combustion, modeling of turbulence and turbulence combustion interaction, etc. in the current models, the computations that were performed using KIVA-II and LeRC3D show that these codes are capable of producing reasonable results. The qualitative insight and trends result from parametric variation of combustor design variables provided by these codes prediction is considered to be a prime factor for reducing development iterations and guiding low emission combustion experiments. The lack of more detailed experimental data has precluded more detailed validation of the codes. As reliable experimental data becomes available, further computations will reveal the capabilities and limitations of these codes and the modifications necessary to overcome the limitations.

\section{$\underline{\text { References }}$}

1. Amsden, A.A., O'Rourke, P.J., and Butler, T.D., "KIVA-II: A Computer Program for Chemically Reactive Flows With Sprays," Los Alamos National Laboratory, LA-11560-MS, May 1989.

2. Nguyen, H.L. and Ying, S.J., "Critical Evaluation of Jet-A Spray Combustion Using Propane Chemical Kinetics in Gas Turbine Combustion SImulated by KIVA-II," AIAA Paper 90-2439, July 1990 (also, NASA TM-103173).

3. Nguyen, H.L. and Wey, M.J., "Evaluation of a Hybrid Kinetics/Mixing-Controlled Combustion Model for Turbulent Premixed and Diffusion Combustion Using KIVA-II." AIAA Paper 90-2450, July 1990 (also, NASA TM-103196).

4. Butler, T.D., "Analysis of an Air Assist Atomizer," Los Alamos National Laboratory, private communication, May 1990.

5. Micklow, G.J., Dogra, A.S., and Nguyen, H.L., "Effect of Vane Twist on the Performance of Dome Swirlers for Gas Turbine Airblast Atomizers," AIAA Paper 90-1955, July 1990 (also, NASA TM-103195).

6. Micklow, G.J. and Nguyen, H.L., "The Design and Performance of Dome Swirlers for Gas Turbine Airblast Atomizers," Paper 89-38, 1989 Fall Meeting, Western States Sections, The Combustion Institute, Pittsburgh, PA, 1989. 
7. Micklow, G.J., Private Communications.

8. Anderson, D., "Effects of Equivalence Ratios and Dwell Time on Exhaust Emissions From an Experimental Premixing Prevaporizing Burner," NASA TM X-71592.
9. Winowich, N.S., Moeykens, S., and Nguyen, H.L., "Three Dimensional Calculation of the Mixing of Radial Dilution Jets from Slanted SLots with a Reactive Cylindrical Crossflow," AIAA Paper 91-2081, June 1991.
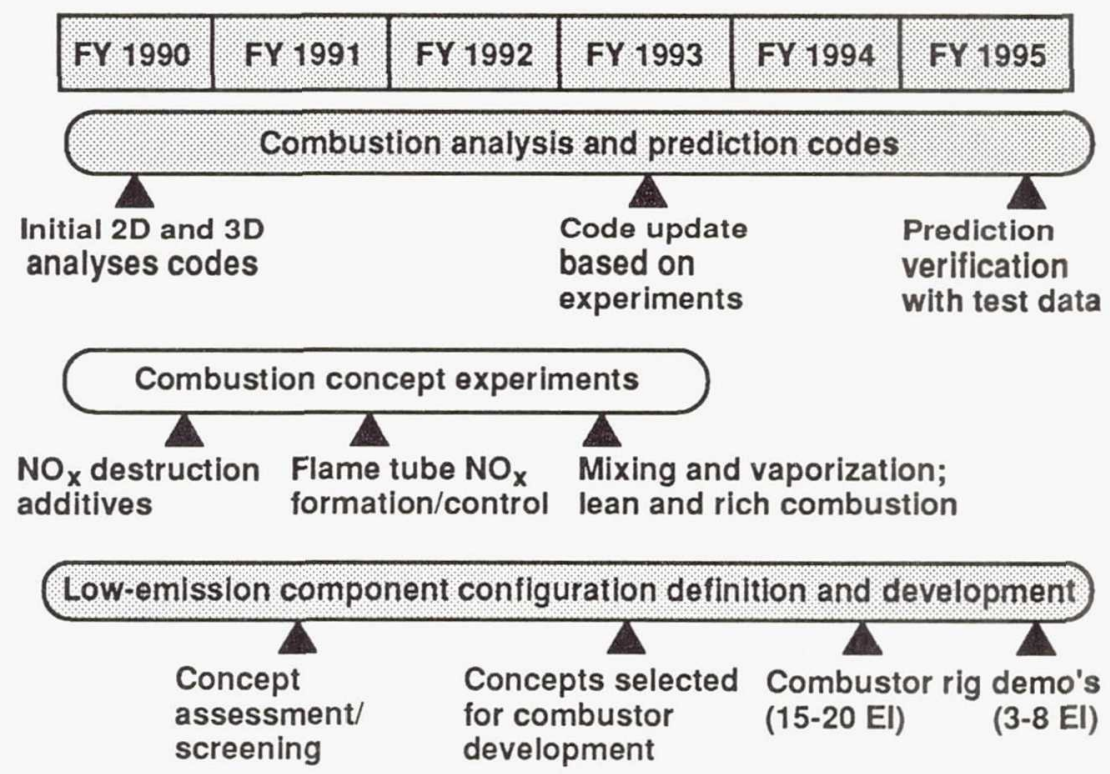

Figure 1.-HSR combustion analytical research key milestones.

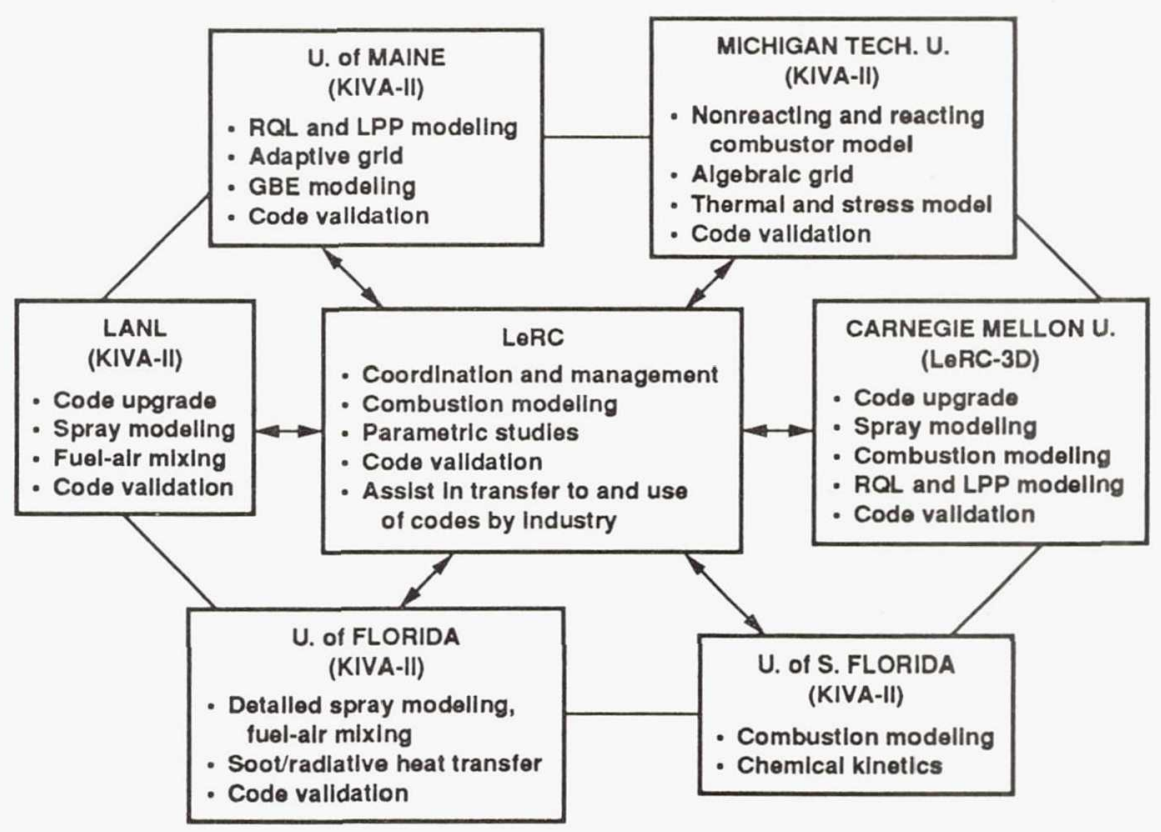

Figure 2.-HSR combustion analytical research organization and activities listing. 
Physics

Turbulent compressible flow of reacting multicomponent gas mixture with liquid spray

$\kappa-\varepsilon$ turbulence model with wall functions

Combustion models:

Chemical kinetics controlled, mixing controlled model

NOx formation model: Extended Zeldovich mechanism

Spray model:

Stochastic model, vaporization, coalescence, breakup

Soot formation/oxidation

Radiation heat transfer

Figure 3.- Key features of computer code KIVA-II.

\section{Physics}

Turbulent compressible flow of reacting multicomponent gas mixture with liquid spray

Turbulence models: $\kappa-\varepsilon$ turbulence model with wall functions

Low Reynolds no. $\kappa-\varepsilon$ model (Chen \& Patel)

RNG-based $\kappa-\varepsilon$ model

Combustion models:

Chemical kinetics controlled Mixing controlled

NO formation model:

Zeldovich mechanism

Spray model:

Lagrangian model of Raju \&

Sirignano

Figure 4.-Key features of computer code LeRC3D.
2D or 3D time-dependent finite difference code

Arbitrary mesh

ICE method with conjugate residual iteration

Optimal quasi-second-order upwind convection
Numerical method

Grid generation:

Algebraic method using transfinite interpolation

Flow algorithm:

Finite-volume, LU, implicit

Code:

Efficient and robust 
KIVA azimuthal velocity comparison

Calc $=070889$, vte $=180,30 w t e=22,22 ; k$-e
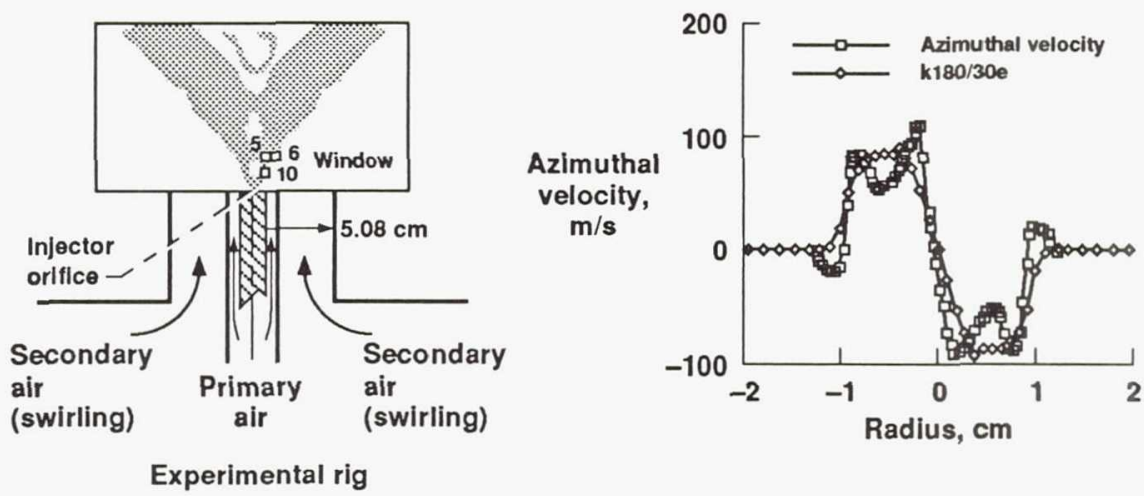

Figure 5.-Comparison of predicted and measured air azimuthal velocity of an experimental air assist atomizer.

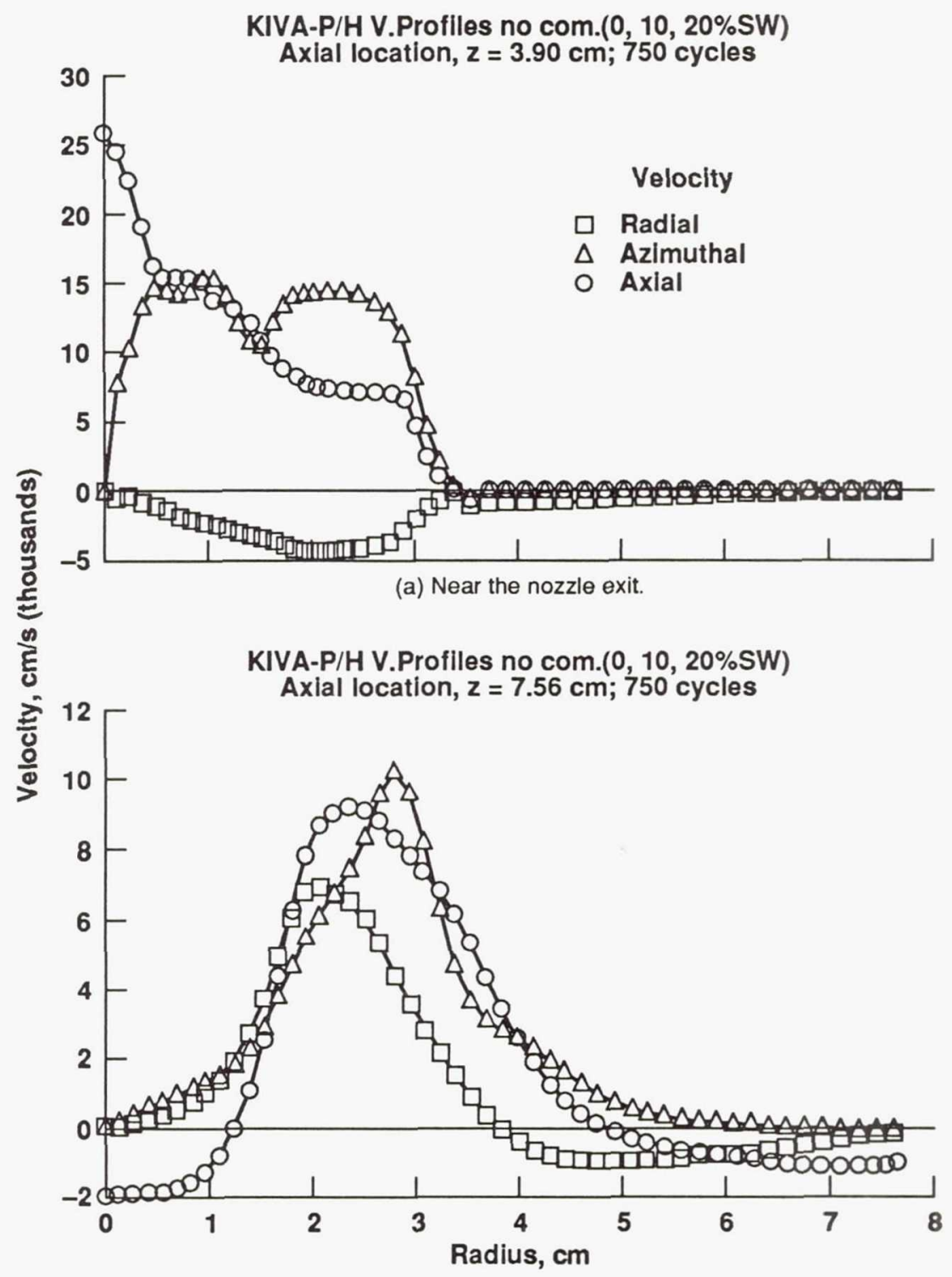

(b) KIVA-II downstream.

Figure 6.-Velocity profiles. 

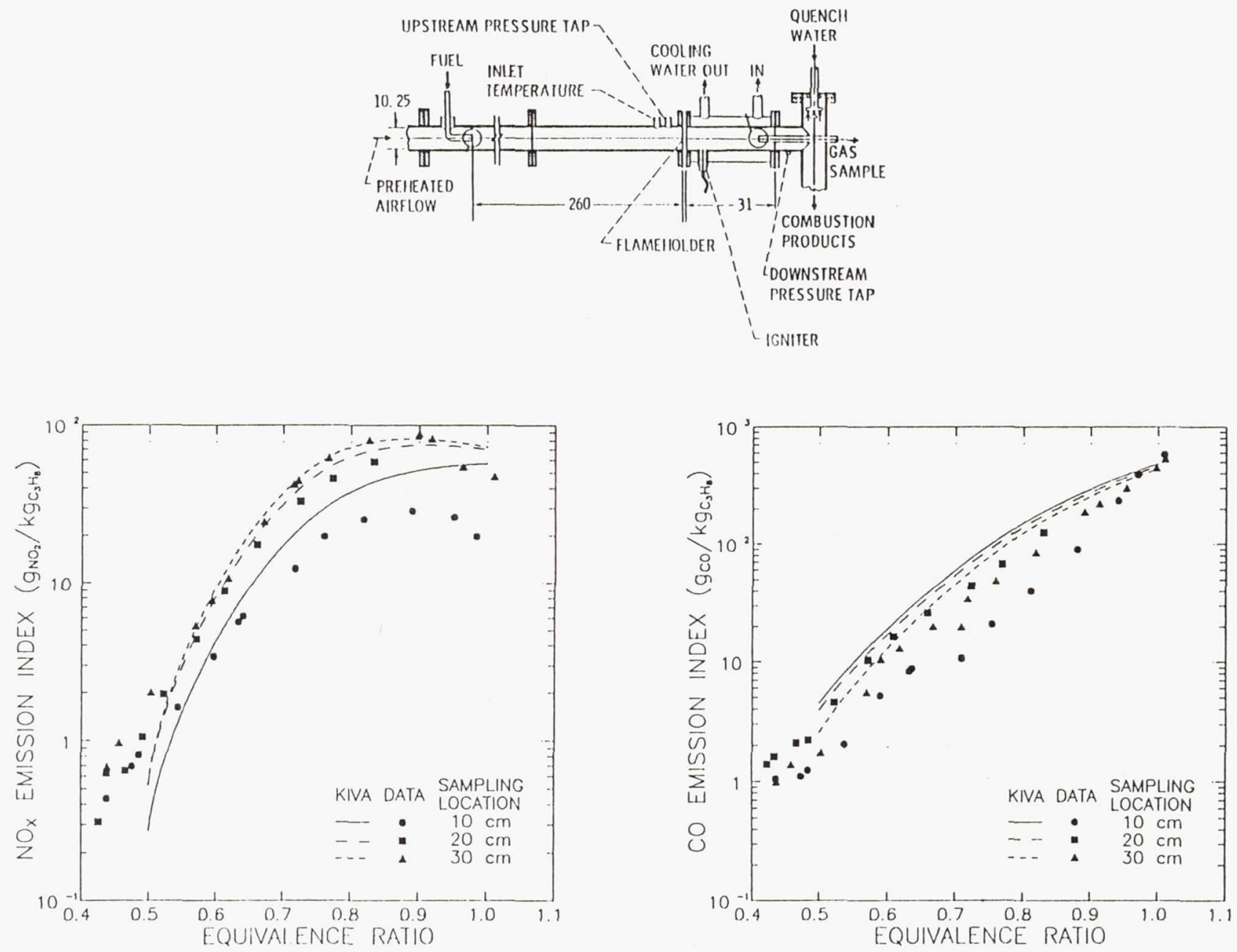

Figure 7.--Comparison of experimental and predicted $\mathrm{NO}_{\mathrm{x}}$ and $\mathrm{CO}$ emission index of a lean premixed prevaporized burner. 

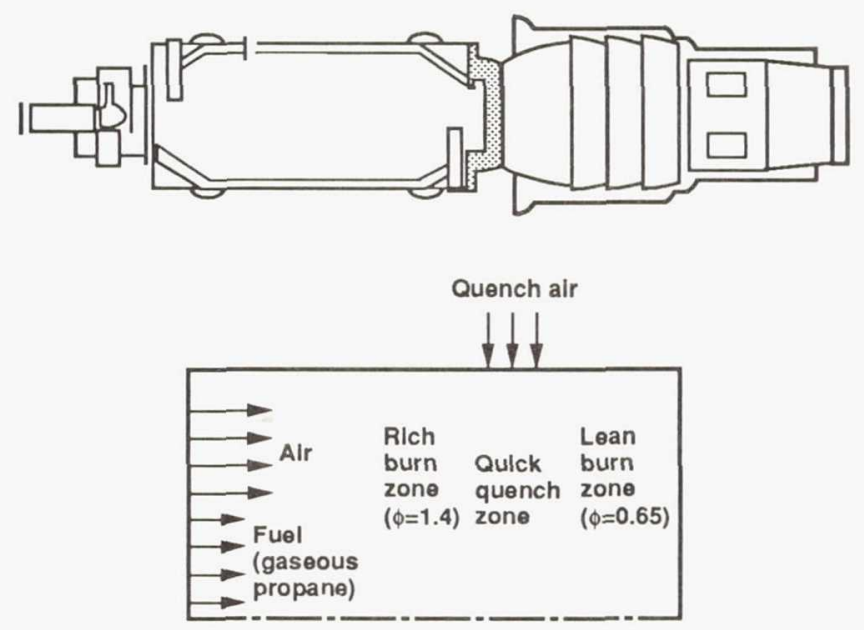

Simplified combustor model

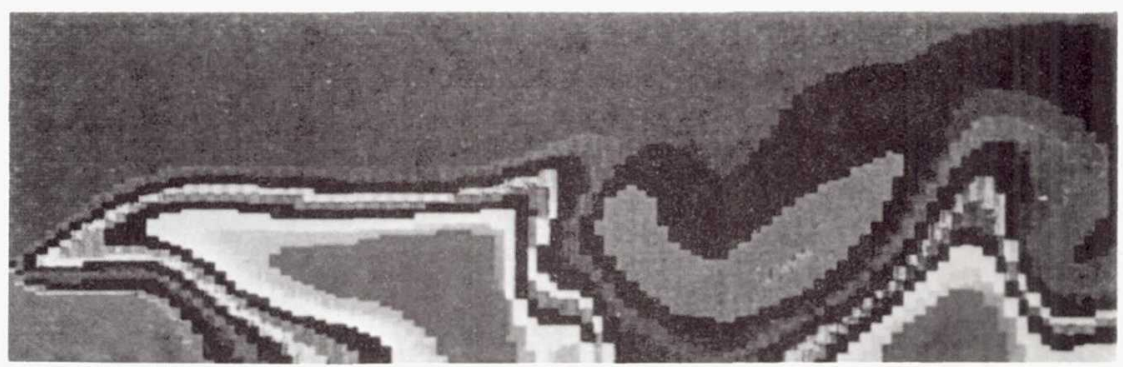

Predicted temperature contours

Figure 8.-Predicted gas temperature profile of a rich burn/quick quench/lean burn combustor. 


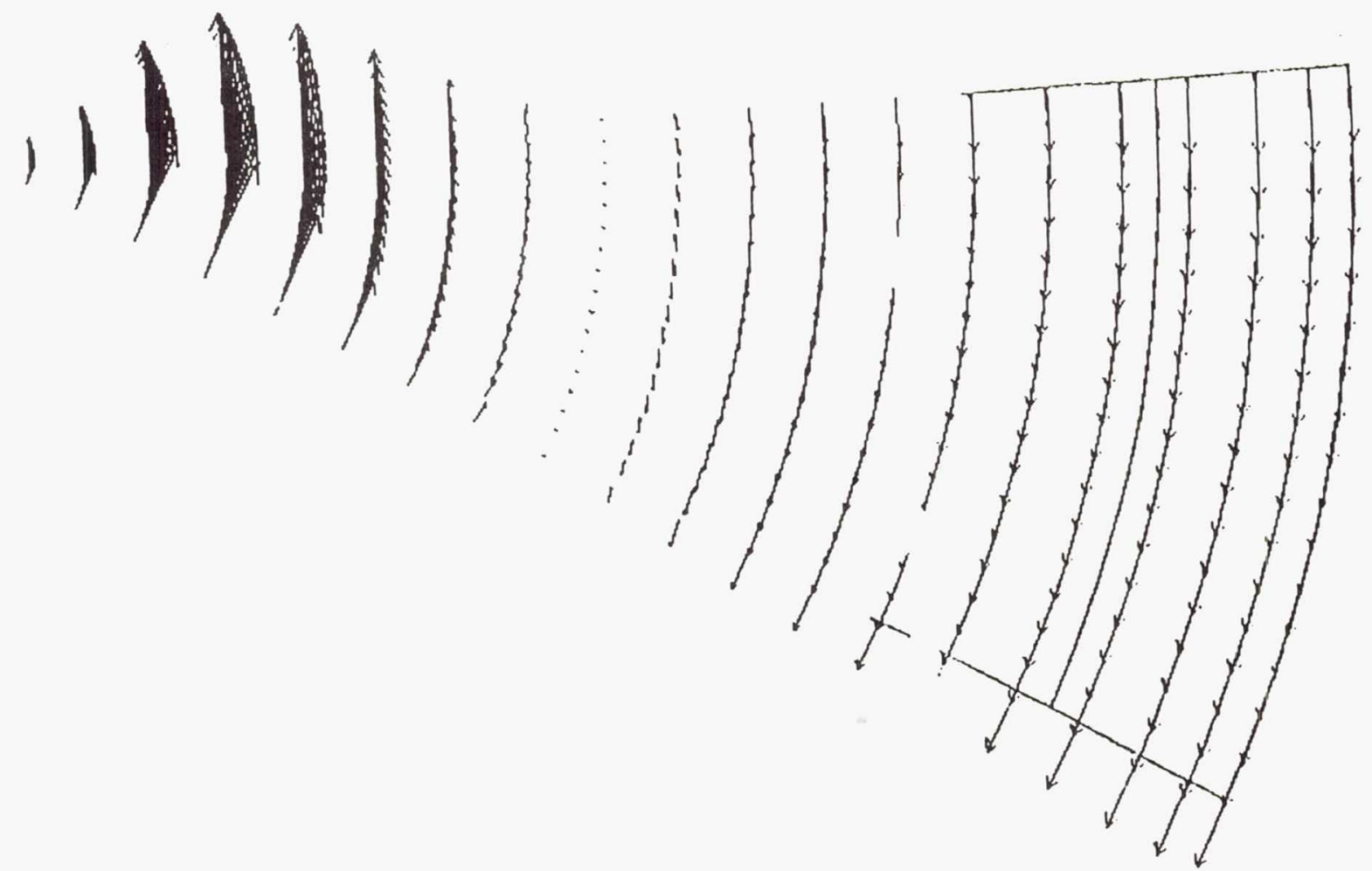

Figure 9.-Predicted velocity vector profile at an axial plane at a downstream location of half a slot length from the slot centerline of a quick quench design of the rich burn/quick quench/lean burn combustor.

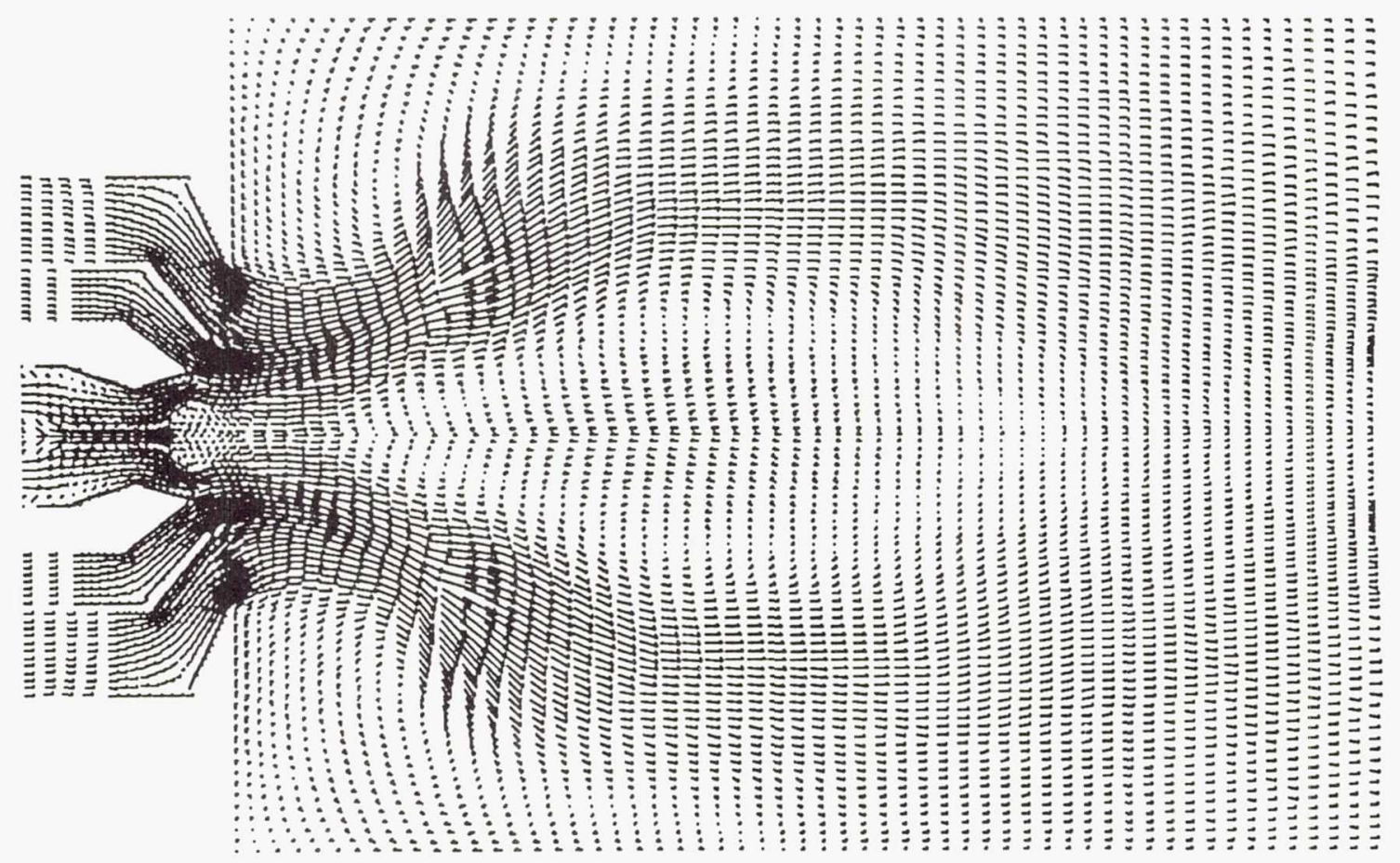

Figure 10. - Predicted rich burner flow field characteristics of a rich burn/quick quench/lean burn combustor. 


\section{Report Documentation Page}

\section{Report No. NASA TM-104521 \\ AIAA-91-2252}

\section{Title and Subtitle}

Analytical Combustion/Emissions Research Related to the

NASA High-Speed Research Program

\section{Government Accession No. \\ 3. Recipient's Catalog No.}

.

5. Report Date

6. Performing Organization Code

8. Performing Organization Report No. E- 6392

H. Lee Nguyen

10. Work Unit No.

537-02-20

9. Performing Organization Name and Address

National Aeronautics and Space Administration

11. Contract or Grant No.

Lewis Research Center

Cleveland, Ohio 44135-3191

12. Sponsoring Agency Name and Address

National Aeronautics and Space Administration

Washington, D.C. 20546-0001

13. Type of Report and Period Covered

Technical Memorandum

14. Sponsoring Agency Code

15. Supplementary Notes

Prepared for the 27th Joint Propulsion Conference cosponsored by AIAA, SAE, ASME, and ASEE, Sacramento, California, June 24-27, 1991. Responsible person, H. Lee Nguyen, (216) 433-3574.

\section{Abstract}

Increasing the pressure and temperature of the engines of new generation of supersonic airliners increases the emissions of nitrogen oxides $\left(\mathrm{NO}_{\mathrm{x}}\right)$ to a level that would have an adverse impact on the Earth's protective ozone layer. In the process of evolving the implementing low emissions combustor technologies, NASA Lewis Research Center has pursued a combustion analysis program to guide combustor design processes, to identify potential concepts of greatest promise, and to optimize them at low cost, with short turn-around time. The approach is to upgrade and apply advanced computer programs for gas turbine applications. Efforts have been made in further improving the code capabilities of modeling the physics and the numerical method of solution. Then test cases and measurements from experiments are used for code validation. To provide insight into the combustion process and combustor design, twodimensional and three-dimensional codes such as KIVA-II and LeRC 3-D have been used. These codes are operational and calculations have been performed to guide low emissions combustion experiments.

\begin{tabular}{|l|l|l|l|}
\hline $\begin{array}{l}\text { 17. Key Words (Suggested by Author(s)) } \\
\text { High speed research } \\
\text { Analytical combustion research } \\
\text { Gas turbine engine } \\
\text { Emission }\end{array}$ & $\begin{array}{l}\text { 18. Distribution Statement } \\
\text { Unclassified - Unlimited } \\
\text { Subject Category } 07\end{array}$ \\
\hline $\begin{array}{l}\text { 19. Security Classif. (of the report) } \\
\text { Unclassified }\end{array}$ & 20. Security Classif. (of this page) \\
Unclassified & 21. No. of pages & 12 & 22. Price* \\
\hline
\end{tabular}

